\title{
Penerapan Metode Learning Vector Quantization (LVQ) untuk Mendeteksi Penyalahgunaan Narkoba
}

\author{
Berny Pebo Tomasouw ${ }^{1}$, Salmon Notje Aulele ${ }^{2}$ \& Monalisa E. Rijoly ${ }^{3}$ \\ 1,2,3Jurusan Matematika FMIPA Universitas Pattimura \\ ${ }^{1}$ Corresponding author: bptomasouw@gmail.com
}

\begin{abstract}
Abstrak. Dalam penelitian ini, metode LVQ akan diterapkan untuk mendeteksi penyalahgunaan narkoba berdasarkan gejala-gejala yang dialami seseorang. Untuk mendapatkan tingkat akurasi terbaik, maka data pelatihan dan data pengujian dibagi ke dalam tiga skema pembagian data yakni $60 / 40,70 / 30$ dan 80/20. Setelah dilakukan proses pelatihan dan pengujian menggunakan metode LVQ dengan berbagai variasi nilai laju pembelajaran dan jumlah epoch, maka diperoleh tingkat akurasi terbaik sebesar $86.7 \%$ pada skema pembagian data 70/30 dengan laju pembelajaran $\alpha=$ 0.001 dan $\alpha=0.005$.
\end{abstract}

Kata kunci: deteksi, LVQ, metode, narkoba, penyalahgunaan

\begin{abstract}
In this research, the LVQ method will be applied to detect drug abuse based on the symptoms experienced by a person. To get the best level of accuracy, the training data and testing data are divided into three data allocation schemes, namely 60/40,70/30 and 80/20. After the training and testing process was carried out using the LVQ method with various variations in the value of the learning rate and the number of epochs, the best accuracy rate was $86.7 \%$ at the data allocation scheme $70 / 30$ with the learning rate $\alpha=0.001$ and $\alpha=0.005$.
\end{abstract}

Keywords: abuse, detect, drug, method, LVQ, .

\section{Pendahuluan}

Masalah penyalahgunaan narkoba di Indonesia sudah sangat memprihatinkan. Hal ini disebabkan beberapa faktor antara lain karena Indonesia yang terletak pada posisi di antara tiga benua dan mengingat perkembangan ilmu pengetahuan dan teknologi, maka pengaruh globalisasi serta arus transportasi yang sangat maju dan pergeseran nilai materialistis dengan dinamika sasaran opini peredaran gelap narkoba. Kekhawatiran ini semakin dipertajam akibat maraknya peredaran gelap narkoba yang telah merebak di segala lapisan masyarkat.

Faktor minimnya pengetahuan masyarakat tentang penggunaan narkoba menyebabkan sulitnya masyarakat awam mengidentifikasi seseorang atau pun anggota keluarganya yang telah menjadi korban penyalahgunaan narkoba. Banyaknya efek negatif yang terjadi terhadap korban narkoba ini menjadi motivasi untuk melakukan penelitian tentang deteksi 
penyalahgunaan narkoba berdasarkan gejala-gejala yang dirasakan sehingga bisa diketahui apakah seorang itu telah terkena pengaruh narkoba atau tidak agar segera ditindaklanjuti.

Salah satu metode yang paling baik untuk masalah kelasifikasi adalah metode Learning Vector Quantization (LVQ). Metode ini termasuk dalam Jaringan Syaraf Tiruan (JST) yang mana merupakan salah satu jenis jenis jaringan yang berbasis kompetitif dimana dari nilai keluaran yang diberikan neuron dalam layer keluaran hanya neuron pemenang saja yang diperhatikan. Neuron pemenang tersebut yang akan mengalami pembaruan bobot. LVQ memiliki kelebihan seperti nilai eror lebih kecil dibandingkan metode lain serta model yang dihasilkan dapat diperbaharui secara bertahap.

Metode LVQ ini sudah banyak diterapkan untuk menyelesaikan berbagai permasalahan, antara lain untuk pengenalan wajah (Heranurweni [1]), mengklasifikasi status gizi anak (Budianita \& Widodo [2]), memprediksi jurusan yang akan diminati pada SMA PGRI 1 Banjarbaru (Meliawati, R.dkk [3]), mengklasifikasi kualitas air sungai (Hamidi, R. dkk. [4]), serta mendiagnosa penyakit dalam (Leleury \& Lesnussa [5]). Penelitian-penelitian ini menunjukan bahwa metode LQV memiliki performa dan hasil yang baik.

\subsection{Model Jaringan Learning Vector Quantization (LVQ)}

Model jaringan Learning Vector Quantization merupakan salah satu jenis jaringan saraf tiruan berbasis competitive learning atau winner take all yang terawasi. Suatu lapisan Kompetitif akan secara otomatis belajar unutk mengklasifikasikan vektor-vektor input. Kelas-kelas yang didapatkan sebagai hasil dari lapisan kompetitif ini hanya tergantung pada jarak antara vector-vektor input. Jika 2 vektor input mendekati sama, maka lapisan kompetitif akan meletakan kedua vektor input tersebut ke dalam kelas yang sama.

Arsitektur model jaringan LVQ adalah sebagai berikut (Fausett [6]):

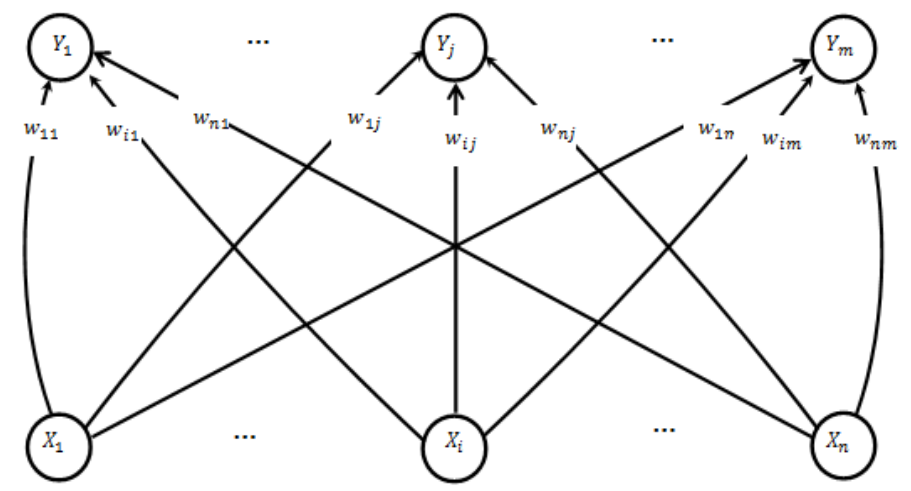

Gambar 1 Jaringan Learning Vector Quantization 


\subsection{Algoritma Learning Vector Quantization (LVQ)}

Motivasi untuk algoritma jaringan LVQ adalah untuk mencari unit output yang terdekat dengan vektor input. Jika $x$ dan $w$ merupakan kelas yang sama, maka pindahkan bobot terhadap vektor input baru, jika $x$ dan $w$ merupakan kelas-kelas yang berbeda, maka pindahkan bobot dari input vektor.

Algoritma yang digunakan adalah sebagai berikut (Fausett [6]):

Langkah $0 . \quad$ Inisialisasi vektor referensi

Inisialisasi laju pelatihan (learning rate) $\alpha(0)$.

Langkah 1. Bila kondisi STOP belum dipenuhi, kerjakan Langkah $2-6$.

Langkah 2. Untuk setiap vektor input training kerjakan Langkah 3-4

Langkah 3. Dapatkan $j$ sedemikian hingga $\left\|x-w_{i j}\right\|$ minimum.

Langkah 4. Update $W_{i j}$ sebagai berikut

Jika $C_{j}=T$, maka

$W_{i j}($ baru $)=W_{i j}($ lama $)+\alpha\left[x_{i}-W_{i j}(\right.$ lama $\left.)\right]$

Jika $C_{j} \neq T$, maka

$W_{i j}($ baru $)=W_{i j}($ lama $)-\alpha\left[x_{i}-W_{i j}(\right.$ lama $\left.)\right]$

Langkah 5. Reduksi laju pelatihan

$\alpha=\alpha * \operatorname{Dec} \alpha$

Langkah 6. Tes kondisi STOP

Misal: 1. Dengan membatasi jumlah iterasi

2. Setelah $\alpha$ mencapai nilai toleransi

dengan

$x \quad:$ vektor training $\left(x_{1}, x_{2}, \ldots, x_{n}\right)$

$T \quad$ : kategori/target yang benar untuk vektor training

$W_{j} \quad:$ vektor bobot untuk unit output ke-j $\left(w_{1 j}, \ldots, w_{i j}, \ldots, w_{n j}\right)$

$C_{j} \quad:$ kategori/kelas hasil komputasi oleh unit output $j$

$\left\|x_{i}-W_{j}\right\| \quad$ : jarak Euclidean antara vektor input dengan unit output

\subsection{Narkoba}

Narkoba adalah adalah singkatan dari Narkotika, psikotropika dan bahan adiktif lainnya. Sesuai dengan undang-undang narkoba nomor 35 tahun 2009 tentang narkotika, narkoba dibagi dalam 3 unsur yaitu narkotika, psikotropika dan bahan adiktif lainnya. Narkotika adalah zat atau obat yang berasal dari tanaman atau bukan tanaman baik sintetis maupun semisintesis, yang dapat menyebabkan penurunan atau perubahan kesadaran, hilangnya rasa, mungurangi sampai menghilangkan rasa nyeri dan dapat menimbulkan ketergantungan. Menurut Dirjosiswono [7] bahwa pengertian Narkotika adalah zat yang bisa menimbulkan pengaruh Tertentu bagi yang menggunakannya dengan memasukan kedalam tubuh. "pengaruh tersebut bisa berupa pembiusan, hilangnya rasa sakit, 
rangsangan semangat dan halusinasi atau timbulnya khayalan-khayalan. Sifat-sifat tersebut yang diketahui dan ditemukan dalam dunia medis bertujuan dimanfaatkan bagi pengobatan dan kepentingan manusia rasa sakit dan lain-lain.

Menurut UU No.5 Tahun 1997, psikotropika merupakan zat atau obat, baik alamiah maupun sintetik bukan narkotika yang berkhasiat, psikoaktif melalui pengaruh selektif menurut susunan syaraf pusat yang menyebabkan perubahan khas pada aktifitas mental dan perilaku. Zat/obat yang dapat menurunkan aktivitas otak atau merangsang susunan syaraf pusat dan menimbulkan kelainan Perilaku disertai dengan timbulnya halusinasi (menghayal), ilusi, gangguan cara berpikir perubahan alam perasaan dan dapat menyebabkan ketergantungan serta mempunyai efek stimulasi (merangsang) bagi para pemakainya. Psikotropika (Dirjosisworo [7]) adalah zat atau bukan narkotika baik alamiah maupun sintesis yang memiliki khasiat psikoaktif melalui pengaruh selektif pada susunan saraf pusat yang menyebabkan perubahan khas pada aktivitas normal dan perilaku.

Sedangkan zat adiktif adalah obat serta bahan-bahan aktif yang apabila di komsumsi oleh organisme hidup dapat menyebabkan kerja biologi serta menimbulkan ketergantungan atau adiksi yang sulit di hentikan dan berefek ingin menggunkannya secara terus-menerus yang jika dihentikan dapat memberikan efek lelah luar biasa

\section{Data dan Variabel Penelitian}

Dalam penelitian ini, data yang digunakan adalah data 101 orang pasien rawat jalan yang diperoleh dari BNN Provinsi Maluku. Data dari 101 orang tersebut lengkap dengan 23 jenis gejala dan jenis narkoba yang dipakai. Berdasarkan data yang diperoleh maka ditetapkan 4 kelas yang akan digunakan sebagai target seperti pada tabel di bawah ini

Tabel 1 Data target jenis narkoba

\begin{tabular}{|c|l|}
\hline Kelas & Jenis Narkoba yang digunakan \\
\hline 1 & Sabu \\
\hline 2 & Ganja \\
\hline 3 & Lem \\
\hline 4 & Sintetik (Pethidin+Methadon) \\
\hline
\end{tabular}

Sedangkan gejala-gejala yang akan digunakan sebagai variabel input dapat dilihat pada tabel berikut ini 
Tabel 2 Gejala dan Inisilisasi Variabel

\begin{tabular}{|c|l|c|}
\hline No & \multicolumn{1}{|c|}{ Gejala } & Inisialisasi \\
\hline 1 & Muda tersinggung & $x_{1}$ \\
\hline 2 & Kecanduan & $x_{2}$ \\
\hline 3 & Depresi & $x_{3}$ \\
\hline 4 & Agitasi & $x_{4}$ \\
\hline 5 & Imsomnia & $x_{5}$ \\
\hline 6 & Kerusakan Ginjal & $x_{6}$ \\
\hline 7 & Gangguan Sex & $x_{7}$ \\
\hline 8 & Paru-paru terganggu & $x_{8}$ \\
\hline 9 & Mudah lelah & $x_{9}$ \\
\hline 10 & Muntah & $x_{10}$ \\
\hline 11 & Berkeringat & $x_{11}$ \\
\hline 12 & Gelisa & $x_{12}$ \\
\hline 13 & Mental terganggu & $x_{13}$ \\
\hline 14 & Sembelit & $x_{14}$ \\
\hline 15 & Nafsu makan hilang & $x_{15}$ \\
\hline 16 & Keracunan & $x_{16}$ \\
\hline 17 & Paranoid & $x_{17}$ \\
\hline 18 & Susunan syaraf pusat rusak & $x_{18}$ \\
\hline 19 & Mudah gugup & $x_{19}$ \\
\hline 20 & Pusing & $x_{20}$ \\
\hline 21 & Detak jantung meningkat & $x_{21}$ \\
\hline 22 & Otot melemah & $x_{22}$ \\
\hline 23 & Susah buang air kecil & $x_{23}$ \\
\hline & & \\
\hline
\end{tabular}

\section{Hasil dan Pembahasan}

Data yang digunakan dalam penelitian ini akan dibagi menjadi dua bagian yakni data pelatihan dan data pengujian dengan beberapa skema pembagian seperti pada tabel berikut.

Tabel 3 Skema pembagian data

\begin{tabular}{|c|c|c|}
\hline No & Skema Pembagian & Keterangan \\
\hline \multirow[b]{2}{*}{1} & \multirow{2}{*}{$60 / 40$} & 61 data pelatihan \\
\hline & & 40 data pengujian \\
\hline \multirow[t]{2}{*}{2} & \multirow{2}{*}{$70 / 30$} & 71 data Pelatihan \\
\hline & & 30 data pengujian \\
\hline \multirow{2}{*}{3} & \multirow{2}{*}{$80 / 20$} & 81 data Pelatihan \\
\hline & & 20 data pengujian \\
\hline
\end{tabular}




\subsection{Hasil Penelitian}

Data yang telah dibagi akan diproses menggunakan metode LVQ dengan beberapa variasi nilai alfa (laju pembelajarn) dan bantuan software MATLAB sehingga diketahui tingkat akurasi terbaik yang bisa diperoleh.

Tabel 4 Tingkat Akurasi dengan Skema Pembagian Data 60/40

\begin{tabular}{|l|c|c|c|c|c|c|c|c|}
\hline Nilai alfa & $\begin{array}{c}\alpha= \\
0.001\end{array}$ & $\begin{array}{c}\alpha= \\
0.005\end{array}$ & $\begin{array}{c}\alpha= \\
0.008\end{array}$ & $\begin{array}{c}\alpha= \\
0.01\end{array}$ & $\begin{array}{c}\alpha= \\
0.05\end{array}$ & $\begin{array}{c}\alpha= \\
0.08\end{array}$ & $\begin{array}{c}\alpha= \\
0.1\end{array}$ & $\begin{array}{c}\alpha= \\
0.5\end{array}$ \\
\hline $\begin{array}{l}\text { Jumlah } \\
\text { Epoch }\end{array}$ & 20 & 20 & 20 & 20 & 20 & 20 & 20 & 20 \\
\hline $\begin{array}{l}\text { Tingkat } \\
\text { Akurasi }\end{array}$ & $85 \%$ & $85 \%$ & $82.5 \%$ & $\begin{array}{c}82.5 \\
\%\end{array}$ & $\begin{array}{c}77.5 \\
\%\end{array}$ & $\begin{array}{c}77.5 \\
\%\end{array}$ & $\begin{array}{c}77.5 \\
\%\end{array}$ & $\begin{array}{c}72.5 \\
\%\end{array}$ \\
\hline
\end{tabular}

Dari tabel 4 terlihat bahwa hasil pengujian dengan metode LVQ dengan skema pembagian data 60/40 diperoleh hasil terbaik pada nilai $\alpha=0.001$ dan $\alpha=0.005$ dengan tingkat akurasi sebesar $85 \%$, sedangkan jumlah epochnya adalah 20 .

Tabel 5 Tingkat Akurasi dengan Skema Pembagian Data 70/30

\begin{tabular}{|l|c|c|c|c|c|c|c|c|}
\hline Nilai alfa & $\begin{array}{c}\alpha= \\
0.001\end{array}$ & $\begin{array}{c}\alpha= \\
0.005\end{array}$ & $\begin{array}{c}\alpha= \\
0.008\end{array}$ & $\begin{array}{c}\alpha= \\
0.01\end{array}$ & $\begin{array}{c}\alpha= \\
0.05\end{array}$ & $\begin{array}{c}\alpha= \\
0.08\end{array}$ & $\begin{array}{c}\alpha= \\
0.1\end{array}$ & $\begin{array}{c}\alpha= \\
0.5\end{array}$ \\
\hline $\begin{array}{l}\text { Jumlah } \\
\text { Epoch }\end{array}$ & 20 & 20 & 20 & 20 & 20 & 20 & 20 & 20 \\
\hline $\begin{array}{l}\text { Tingkat } \\
\text { Akurasi }\end{array}$ & $86.7 \%$ & $86.7 \%$ & $83.3 \%$ & $83.3 \%$ & $80 \%$ & $80 \%$ & $80 \%$ & $76.7 \%$ \\
\hline
\end{tabular}

Dari tabel 5 terlihat bahwa hasil pengujian dengan metode LVQ dengan skema pembagian data 70/30 diperoleh hasil terbaik pada nilai $\alpha=0.001$ dan $\alpha=0.005$ dengan tingkat akurasi sebesar $86.7 \%$, sedangkan jumlah epochnya adalah 20 .

Tabel 6 Tingkat Akurasi dengan Skema Pembagian Data 80/20

\begin{tabular}{|l|c|c|c|c|c|c|c|c|}
\hline Nilai alfa & $\begin{array}{c}\alpha= \\
0.001\end{array}$ & $\begin{array}{c}\alpha= \\
0.005\end{array}$ & $\begin{array}{c}\alpha= \\
0.008\end{array}$ & $\begin{array}{c}\alpha= \\
0.01\end{array}$ & $\begin{array}{c}\alpha= \\
0.05\end{array}$ & $\begin{array}{c}\alpha= \\
0.08\end{array}$ & $\begin{array}{c}\alpha= \\
0.1\end{array}$ & $\begin{array}{c}\alpha= \\
0.5\end{array}$ \\
\hline $\begin{array}{l}\text { Jumlah } \\
\text { Epoch }\end{array}$ & 20 & 20 & 20 & 20 & 20 & 20 & 20 & 20 \\
\hline $\begin{array}{l}\text { Tingkat } \\
\text { Akurasi }\end{array}$ & $10 \%$ & $10 \%$ & $10 \%$ & $35 \%$ & $10 \%$ & $10 \%$ & $10 \%$ & $25 \%$ \\
\hline
\end{tabular}


Dari tabel 6 terlihat bahwa hasil pengujian dengan metode LVQ dengan skema pembagian data 80/20 diperoleh hasil terbaik pada nilai $\alpha=0.01$ dengan tingkat akurasi sebesar 35\%, sedangkan jumlah epochnya adalah 20.

\subsection{Pembahasan}

Berdasarkan tabel 4, 5 dan 6 dapat disimpulkan bahwa tingkat keakuratan terbaik yang diperoleh adalah $86.7 \%$ dengan nilai $\alpha=0.001$ dan $\alpha=0.005$ pada skema pembagian 70/30. Selanjutnya, perbandingan secara rinci hasil pengujian dari metode LVQ dengan data aktual dapat dilihat pada tabel-tabel di bawah ini.

Tabel 7 Hasil Pengujian pada Skema Pembagian Data 60/40

\begin{tabular}{|l|c|c|c|c|c|c|c|c|c|c|}
\hline \multicolumn{1}{|c|}{ Data ke - } & $\mathbf{1}$ & $\mathbf{2}$ & $\mathbf{3}$ & $\mathbf{4}$ & $\mathbf{5}$ & $\mathbf{6}$ & $\mathbf{7}$ & $\mathbf{8}$ & $\mathbf{9}$ & $\mathbf{1 0}$ \\
\hline $\begin{array}{l}\text { Target Data } \\
\text { Aktual }\end{array}$ & 1 & 1 & 1 & 1 & 1 & 1 & 1 & 1 & 1 & 1 \\
\hline $\begin{array}{l}\text { Hasil } \\
\text { Program }\end{array}$ & 1 & 1 & 1 & 1 & 1 & 1 & 1 & 1 & 1 & 1 \\
\hline \multicolumn{1}{|c|}{ Data ke - } & $\mathbf{1 1}$ & $\mathbf{1 2}$ & $\mathbf{1 3}$ & $\mathbf{1 4}$ & $\mathbf{1 5}$ & $\mathbf{1 6}$ & $\mathbf{1 7}$ & $\mathbf{1 8}$ & $\mathbf{1 9}$ & $\mathbf{2 0}$ \\
\hline $\begin{array}{l}\text { Target Data } \\
\text { Aktual }\end{array}$ & 1 & 1 & 2 & 2 & 2 & 2 & 2 & 2 & 2 & 2 \\
\hline $\begin{array}{l}\text { Hasil } \\
\text { Program }\end{array}$ & 1 & 1 & 2 & 2 & 2 & 1 & 2 & 1 & 1 & 1 \\
\hline \multicolumn{1}{|c|}{ Data ke - } & $\mathbf{2 0}$ & $\mathbf{2 1}$ & $\mathbf{2 2}$ & $\mathbf{2 3}$ & $\mathbf{2 4}$ & $\mathbf{2 5}$ & $\mathbf{2 6}$ & $\mathbf{2 7}$ & $\mathbf{2 8}$ & $\mathbf{3 0}$ \\
\hline $\begin{array}{l}\text { Target Data } \\
\text { Aktual }\end{array}$ & 2 & 3 & 3 & 3 & 3 & 3 & 3 & 3 & 3 & 3 \\
\hline $\begin{array}{l}\text { Hasil } \\
\text { Program }\end{array}$ & 1 & 3 & 3 & 3 & 3 & 3 & 3 & 3 & 3 & 3 \\
\hline \multicolumn{1}{|c|}{ Data ke - } & $\mathbf{3 1}$ & $\mathbf{3 2}$ & $\mathbf{3 3}$ & $\mathbf{3 4}$ & $\mathbf{3 5}$ & $\mathbf{3 6}$ & $\mathbf{3 7}$ & $\mathbf{3 8}$ & $\mathbf{3 9}$ & $\mathbf{4 0}$ \\
\hline $\begin{array}{l}\text { Target Data } \\
\text { Aktual }\end{array}$ & 3 & 3 & 3 & 3 & 3 & 3 & 3 & 3 & 4 & 4 \\
\hline $\begin{array}{l}\text { Hasil } \\
\text { Program }\end{array}$ & 3 & 3 & 2 & 2 & 3 & 3 & 3 & 1 & 4 & 4 \\
\hline
\end{tabular}

Dari tabel diatas terlihat bahwa terjadi kesalahan klasifikasi sebanyak 6 dari total 40 data pengujian. Kesalahan klasifikasi paling banyak terjadi pada kelas 2 dan kelas 3 dari jumlah 6 kesalahan, sedangkan pada kelas 1 dan kelas 4 hasil klasifikasinya benar sesuai dengan target data aktual. 
Tabel 8 Hasil Pengujian pada Skema Pembagian Data 70/30

\begin{tabular}{|l|c|c|c|c|c|c|c|c|c|c|}
\hline \multicolumn{1}{|c|}{ Data ke - } & $\mathbf{1}$ & $\mathbf{2}$ & $\mathbf{3}$ & $\mathbf{4}$ & $\mathbf{5}$ & $\mathbf{6}$ & $\mathbf{7}$ & $\mathbf{8}$ & $\mathbf{9}$ & $\mathbf{1 0}$ \\
\hline $\begin{array}{l}\text { Target Data } \\
\text { Aktual }\end{array}$ & 1 & 1 & 1 & 1 & 1 & 1 & 1 & 1 & 1 & 2 \\
\hline $\begin{array}{l}\text { Hasil } \\
\text { Program }\end{array}$ & 1 & 1 & 1 & 1 & 1 & 1 & 1 & 1 & 1 & 2 \\
\hline \multicolumn{1}{|c|}{ Data ke - } & $\mathbf{1 1}$ & $\mathbf{1 2}$ & $\mathbf{1 3}$ & $\mathbf{1 4}$ & $\mathbf{1 5}$ & $\mathbf{1 6}$ & $\mathbf{1 7}$ & $\mathbf{1 8}$ & $\mathbf{1 9}$ & $\mathbf{2 0}$ \\
\hline $\begin{array}{l}\text { Target Data } \\
\text { Aktual }\end{array}$ & 2 & 2 & 2 & 2 & 2 & 2 & 3 & 3 & 3 & 3 \\
\hline $\begin{array}{l}\text { Hasil } \\
\text { Program }\end{array}$ & 2 & 2 & 1 & 2 & 1 & 1 & 3 & 3 & 3 & 3 \\
\hline \multicolumn{1}{|c|}{ Data ke - } & $\mathbf{2 1}$ & $\mathbf{2 2}$ & $\mathbf{2 3}$ & $\mathbf{2 4}$ & $\mathbf{2 5}$ & $\mathbf{2 6}$ & $\mathbf{2 7}$ & $\mathbf{2 8}$ & $\mathbf{2 9}$ & $\mathbf{3 0}$ \\
\hline $\begin{array}{l}\text { Target Data } \\
\text { Aktual }\end{array}$ & 3 & 3 & 3 & 3 & 3 & 3 & 3 & 3 & 4 & 4 \\
\hline $\begin{array}{l}\text { Hasil } \\
\text { Program }\end{array}$ & 3 & 3 & 3 & 3 & 3 & 3 & 3 & 2 & 4 & 4 \\
\hline
\end{tabular}

Dari tabel diatas terlihat bahwa terjadi kesalahan klasifikasi sebanyak 4 dari total 30 data pengujian. Kesalahan klasifikasi paling banyak terjadi pada kelas 2 dengan jumlah 3 kesalahan sedangkan pada kelas 3 terjadi 1 kesalahan klasifikasi. Di sisi lain data kelas 1 dan kelas 4 berhasil diklasifikasikan dengan benar sesuai target data aktualnya.

Tabel 9 Hasil Pengujian pada Skema Pembagian Data 80/20

\begin{tabular}{|l|c|c|c|c|c|c|c|c|c|c|}
\hline \multicolumn{1}{|c|}{ Data ke - } & $\mathbf{1}$ & $\mathbf{2}$ & $\mathbf{3}$ & $\mathbf{4}$ & $\mathbf{5}$ & $\mathbf{6}$ & $\mathbf{7}$ & $\mathbf{8}$ & $\mathbf{9}$ & $\mathbf{1 0}$ \\
\hline $\begin{array}{l}\text { Target Data } \\
\text { Aktual }\end{array}$ & 1 & 1 & 1 & 1 & 1 & 1 & 2 & 2 & 2 & 2 \\
\hline $\begin{array}{l}\text { Hasil } \\
\text { Program }\end{array}$ & 3 & 3 & 3 & 3 & 3 & 3 & 3 & 3 & 3 & 3 \\
\hline \multicolumn{1}{|c|}{ Data ke - } & $\mathbf{1 1}$ & $\mathbf{1 2}$ & $\mathbf{1 3}$ & $\mathbf{1 4}$ & $\mathbf{1 5}$ & $\mathbf{1 6}$ & $\mathbf{1 7}$ & $\mathbf{1 8}$ & $\mathbf{1 9}$ & $\mathbf{2 0}$ \\
\hline $\begin{array}{l}\text { Target Data } \\
\text { Aktual }\end{array}$ & 2 & 3 & 3 & 3 & 3 & 3 & 3 & 3 & 4 & 4 \\
\hline $\begin{array}{l}\text { Hasil } \\
\text { Program }\end{array}$ & 3 & 3 & 3 & 3 & 3 & 3 & 3 & 3 & 3 & 3 \\
\hline
\end{tabular}

Dari tabel diatas terlihat bahwa terjadi kesalahan klasifikasi sebanyak 13 dari total 20 data pengujian. Kesalahan klasifikasi paling banyak terjadi pada kelas 1, kelas 2 dan kelas 4. Di sisi lain data kelas 3 diklasifikasikan dengan benar sesuai target data aktualnya.

\section{Kesimpulan}

Berdasarkan hasil penelitian dapat disimpulkan bahwa klasifikasi dengan metode LVQ pada tiga skema pembagian data diperoleh hasil tingkat akurasi terbaik pada skema 70/30 
yaitu sebesar $86.7 \%$ dengan laju pembelajaran $\alpha=0.001$ dan $\alpha=0.005$. Hal ini berarti metode LVQ dapat mendeteksi dengan baik penyalahgunaan narkoba berdasarkan gejalagejala yang dirasakan.

\section{$5 \quad$ Daftar Pustaka}

[1] Heranurweni, 2010, Pengenalan Wajah Menggunakan Learning Vector Quantization (LVQ), Prosiding Seminar Nasional Sains Dan Teknologi.

[2] Budianita, E. \& Prijodiprodjo, W., 2013, Penerapan Learning Vector Quantization (LVQ) untuk Klasifikasi Status Gizi Anak, IJCCS (Indonesian Journal of Computing and Cybernetics Systems), 7(2).

[3] Meliawati, R.dkk., 2016, Penerapan Metode Learning Vector Quantization (LVQ) Pada Prediksi Jurusan Di Sma PGRI 1 Banjarbaru, Jurnal KLIK, 3(1).

[4] Hamidi, R. dkk., 2017, Implementasi Learning Vector Quantization (LVQ) untuk Klasifikasi Kualitas Air Sungai, 1(12), hal.1758-1763.

[5] Leleury, Z. A. \& Lesnussa, Y. A., 2016, Sistem Diagnosa Penyakit Dalam dengan Menggunakan Jaringan Saraf Tiruan Metode Backpropagation dan Learning Vektor Quantization. Jurnal Matematika Integratif, 12(2), hal.89-98.

[6] Fausett, L., 1994. Fundamentals of Neural Networks Architectures, Algoritma, and Applications, Prentice Hall, Eglewood cllffs. NJ07632: Florida Institute of Technology.

[7] Dirdjosisworo, S., 1990, Hukum Narkotika Indonesia, Bandung, PT. Citra Aditya Bakti. 